\title{
Pulp properties resulting from different pretreatments of wheat straw and their influence on enzymatic hydrolysis rate
}

\author{
Christine Rossberg ${ }^{\mathrm{a}, *}$, Doreen Steffien ${ }^{\mathrm{b}}$, Martina Bremer ${ }^{\mathrm{a}}$, Swetlana Koenig ${ }^{\mathrm{c}}$, Florbela Carvalheiro ${ }^{\mathrm{d}}$, \\ Luís C. Duarte ${ }^{\mathrm{d}}$, Patrícia Moniz ${ }^{\mathrm{d}}$, Max Hoernicke ${ }^{\mathrm{c}}$, Martin Bertau ${ }^{\mathrm{b}}$, Steffen Fischer ${ }^{\mathrm{a}}$ \\ ${ }^{a}$ Institute of Plant and Wood Chemistry, Dresden University of Technology, Pienner Str. 19, 01723 Tharandt, Germany \\ ${ }^{\mathrm{b}}$ Institute of Chemical Technology, Freiberg University of Mining and Technology, Leipziger Str. 29, 09595 Freiberg, Germany \\ 'Saxon Institute for Applied Biotechnology, Leipzig University, Permoserstr. 15, 04318 Leipzig, Germany \\ ${ }^{\mathrm{d}}$ Laboratório Nacional de Energia e Geologia, I.P., Unidade de Bioenergia, Estrada do Paço do Lumiar 22, 1649-038 Lisboa, Portugal
}

\section{H I G H L I G H T S}

- Process parameters for grinding and pulp storage were optimized.

- Comparison of pulp digestibility after three very different pretreatments.

- Pulp hydrolysis using the novel Penicillium verruculosum cellulase complex.

- Lignin removal is not crucial for enzymatic hydrolysis.

- Autohydrolysis pretreatment enables complete conversion of cellulose to glucose.

\section{A R T I C L E I N F O}

\section{Article history:}

Received 8 April 2014

Received in revised form 23 June 2014

Accepted 26 June 2014

Available online 3 July 2014

\section{Keywords:}

Alkaline pulping

Natural pulping

Autohydrolysis

Wheat straw

Enzymatic hydrolysis

\begin{abstract}
A B S T R A C T
Wheat straw was subjected to three different processes prior to saccharification, namely alkaline pulping, natural pulping and autohydrolysis, in order to study their effect on the rate of enzymatic hydrolysis. Parameters like medium concentration, temperature and time have been varied in order to optimize each method. Milling the raw material to a length of $4 \mathrm{~mm}$ beforehand showed the best cost-value-ratio compared to other grinding methods studied. Before saccharification the pulp can be stored in dried form, leading to a high yield of glucose. Furthermore the relation of pulp properties (i.e. intrinsic viscosity, KLAson-lignin and hemicelluloses content, crystallinity, morphology) to cellulose hydrolysis is discussed.
\end{abstract} (c) 2014 Elsevier Ltd. All rights reserved.

\section{Introduction}

Wheat straw is a fast-growing and abundant agricultural by-product. For instance, $8-13$ million tons per year are readily available in Germany without risking humus reduction (Zeller et al., 2011). As it has no application in the food industry, it could serve as an excellent starting material for the production of cellulose, basic chemicals, lignin and bioethanol in the biorefinery framework. Especially the latter attains increasing importance, since the increasing level of greenhouse gases, the depletion of fossil fuels and the unstable oil market lead to a general interest

\footnotetext{
* Corresponding author. Tel.: +49 (0) 352033831877.

E-mail address: christine.rossberg@forst.tu-dresden.de (C. Rossberg).
}

in alternative transportation fuels (Solomon et al., 2007; Talebnia et al., 2010).

For bioethanol production using lignocellulosic material at least four operations including pretreatment, hydrolysis, fermentation and distillation are necessary (Talebnia et al., 2010). Different pretreatment procedures have been developed in order to increase the accessibility of cellulose by removing hemicelluloses, by breaking down the lignin structure and disrupting the crystalline structure of cellulose (Wang et al., 2012). Furthermore, the removal of lignin can be of advantage, as it has been reported that high lignin contents in the substrates may exert inhibitory effect on the enzymes used for hydrolysis (Rahikainen et al., 2011; Sewalt et al., 1997). Thus different methods have been investigated in order to prepare the carbohydrate fraction for enzymatic hydrolysis, which can be classified into physical (e.g. milling), physico-chemical 